\title{
RESEARCHPAPER
}

\section{Micro-organism isolation and process optimization for lipase production}

\author{
ANKIT KUMAR AND O.P. VERMA \\ Department of Molecular and Cellular Engineering, Jacob School of Biotechnology and Bio-Engineering, Sam \\ Higginbottom Institute of Agriculture, Technology and Sciences, ALLAHABAD (U.P.) INDIA \\ Email : om.verma@shiats.edu.in
}

Article Info :Received : 08.12.2015; Revised : 12.01.2016; Accepted : 08.02.2016

\begin{abstract}
A highly lipase producing Bacillus sp. was isolated from soil under optimized culture conditions such as medium $\mathrm{pH}$, temperature, incubation period, carbon sources, nitrogen sources, lipid sources and various surfactants at different concentrations. The medium $\mathrm{pH}$ of 7.0 and temperature of $40^{\circ} \mathrm{C}$ were optimum for maximizing lipase production. The maximal yield of lipase production by Bacillus sp. was obtained after incubation periods ranging between 3 and 4 days. Casein produced maximum lipase (6.5 \pm 0.015$)$ $\mathrm{U} / \mathrm{ml}$ ) as compared to others nitrogen sources and the medium containing starch was more suitable for maximum lipase (15.60 \pm 0.20$)$ $\mathrm{U} / \mathrm{ml}$ ) production than other carbon sources. The gingily oil was found to be most suitable for maximizing the lipase production $(20.52 \pm 0.20) \mathrm{U} / \mathrm{ml})$. The studies on the influence of surfactants on lipase production revealed that maximum lipase production was induced by tween-20 ((27.10 \pm 0.01$) \mathrm{U} / \mathrm{ml})$.
\end{abstract}

Key words : Lipases, Bacillus sp., Hydrolysis, Optimization

How to cite this paper : Kumar, Ankit and Verma, O.P. (2016). Micro-organism isolation and process optimization for lipase production. Asian J. Bio. Sci., 11 (1) : 71-76 [Special Issue of AFBSAH-2016]. 